\title{
INCLUSÃO SOCIOESPACIAL DE PESSOAS COM DEFICIÊNCIA: UM DESAFIO AO MUNICÍPIO DE JUAZEIRO DO NORTE - CEARÁ
}

\author{
Nathália Gonçalves de Moura ${ }^{1}$ \\ Nághela Gonçalves de Moura ${ }^{2}$ \\ Marcelo Oliveira Santiago ${ }^{3}$
}

\begin{abstract}
RESUMO
Localizada na Região Metropolitana do Cariri cearense, Juazeiro do Norte tem população total de 249.939 habitantes, sendo que 67.453 (26,9\%) possuem algum tipo de deficiência. A significativa incidência deste segmento e suas singularidades impõem um desafio ao município em questão: a inclusão desta fatia da população em seu cotidiano. Esta pesquisa objetivou verificar as condições em que se realizam os deslocamentos de cidadãos com deficiência em Juazeiro do Norte. A pesquisa de cunho qualitativo caracteriza-se por ser um estudo de caso e as técnicas de coleta de dados utilizadas foram a entrevista e visita de campo. Constatou-se na urbe elegida a concepção inadequada dos espaços. Observou-se a ausência de rebaixamentos em canteiros e calçadas, forçando o pedestre com deficiência a deslocar-se pelo asfaltamento e a disposição inadequada de piso tátil, com falhas na continuidade. A cidade de Juazeiro do Norte ainda não atende de modo satisfatório as necessidades de deslocamento de seus munícipes, especialmente os que possuem algum tipo de deficiência. A concepção inadequada dos espaços e equipamentos públicos ou de uso coletivo, somada a ausência de um plano de mobilidade urbana que observe a acessibilidade para pessoas com deficiência, dificultam e até mesmoimpossibilitam que os juazeirenses com deficiência desfrutem com segurança e autonomia, dos espaços, mobiliários, equipamentos urbanos e das edificações.
\end{abstract}

Palavras-chave: Mobilidade Urbana. Planejamento Urbano. Acessibilidade.

Recebido em: 31/03/2016 I Aceito em: 27/07/2016

\footnotetext{
${ }^{1}$ Possui graduação em Bacharelado em Fisioterapia pela Faculdade Leão Sampaio (2014). É pósgraduanda em Docência do Ensino Superior pelo Centro Universitário Doutor Leão Sampaio. E-mail: nathaliagdm@hotmail.com

${ }^{2}$ Possui graduação em Bacharelado em Direito pela Faculdade Paraíso do Ceará (2014).É mestranda em Desenvolvimento Regional Sustentável pela Universidade Federal do Cariri. E-mail: naghela.gm@gmail.com

${ }^{3}$ Possui graduação em Bacharelado em Química pela Universidade Federal do Ceará (1995), Mestrado em Química Inorgânica pela Universidade Federal do Ceará (1998) e Doutorado em Química Inorgânica pela Universidade Federal de São Carlos (2004). Atualmente é professor adjunto da Universidade Federal do Cariri. É Membro colaborador do Mestrado em Desenvolvimento Regional Sustentável na UFCA e do Mestrado em Bioprospecção Molecular na URCA. E-mail: santiago@ufca.edu.br
} 


\section{INTRODUÇÃO}

No Brasil, consoante o censo demográfico de 2010, 23,9\% da população brasileira (45,6 milhões) declarou ter ao menos uma das deficiências investigadas: auditiva, visual, motora ou intelectual (SECRETARIA NACIONAL DEPROMOÇÃO DOS DIREITOS DA PESSOA COM DEFICIÊNCIA, 2012).

Considerando que essas pessoas precisam circular todos os dias nas cidades, por seus passeios e vias públicas, além dos prédios onde estão os serviços de educação, de saúde, de trabalho e de lazer, a Secretaria Nacional de Promoção dos Direitos da Pessoa com Deficiência (2012, p. 25) verificou ainda a condição do entorno das moradias brasileiras. Os dados indicaram que:

[...] somente 5,4\% dos domicílios brasileiros possuíam rampas, 5,8\% dos quais nas faces de quadras de moradias adequadas; $1,9 \%$ em moradias semiadequadas e, $0,2 \% \mathrm{em}$ moradias inadequadas. $O$ item calçada/ passeio estava presente no entorno de $80 \%$ das moradias adequadas, $43 \%$ nas semiadequadas e em somente $9 \%$ das inadequadas. Meio fio / guia foi encontrado em $86,1 \%$ das moradias adequadas, $55,6 \%$ nas semiadequadas e $14,1 \%$ nas inadequadas.

Os dados ora aludidos tornam-se mais preocupantes, pois, consoante a Pesquisa DataSenado Condições de Vida das Pessoas com Deficiência no Brasil (2013), salvo os deficientes auditivos, 41,6\% dos respondentes declararam que já deixaram de frequentar algum ambiente porque a estrutura não estava adaptada as suas necessidades. Assim, a significativa incidência deste segmento no País e a carência de acessibilidade impõem um desafio aos municípios brasileiros: a inclusão de fatias especiais da população no dia a dia das cidades.

Ao contrário do que se possa entender como relativa somente aos meios de transportes coletivos, de bens ou à infraestrutura destinada ao trânsito e aos modos motorizados, a mobilidade abrange uma gama de aspectos, que convergem para o bom desempenho da mobilidade no espaço urbano. Dentre estes aspectos a presente pesquisa discute a mobilidade sustentável, relacionando os deslocamentos urbanos à aspectos sociais, ambientais, políticos, econômicos e de acessibilidade (SOUZA; PASQUALETO, 2013).

Destaque-se que na Convenção das Nações Unidas Sobre os Direitos das Pessoas com Deficiência operou-se uma importante correlação. Este documento, que por versar sobre direitos humanos, foi internalizado pelo Brasil com status de

Ciência e Sustentabilidade - CeS | Juazeiro do Norte v. 2, n. 1, p. 41-55, jan/jun 2016 
Emenda Constitucional, reforça a relevância da deficiência como uma prioridade de direitos humanos e de desenvolvimento sustentável (BRASIL, 2009).Em seu preâmbulo alínea g, a Convenção, assevera "[...] a importância de trazer questões relativas à deficiência ao centro das preocupações da sociedade como parte integrante das estratégias relevantes de desenvolvimento sustentável" (BRASIL, 2009, p. 1).

Incluir as pessoas com deficiência na pauta dos direitos humanos e considerá-las como estratégicas para inaugurar ou alavancar o sustentável desenvolvimento é importante porque, se mantidos no status quo, os sujeitos com deficiência dependerão durante toda sua vida de políticas governamentais assistencialistas e da caridade de terceiros. Mas, quando as pessoas com deficiência usufruem de forma plena de seus direitos humanos, liberdades fundamentais e de sua participação na comunidade, ocorre o fortalecimento de seu senso de pertencimento à sociedade, no avanço do desenvolvimento humano, social e econômico, bem como na eliminação da pobreza (BRASIL, 2009).

A realização desta pesquisa justifica-se pelo fato de ainda serem incipientes os estudos acerca da problemática da acessibilidade e da mobilidade no município de Juazeiro do Norte, consubstanciando-se em um instrumento de denúncia de falta de planejamento urbano e de alerta aos gestores municipais para que estes se preocupem com a inclusão socioespacial de pessoas com deficiência e as questões que lhes são inerentes.

Com o propósito de melhorar as condições em que se realizam os deslocamentos no contexto urbano e contribuir para o acesso universal às cidades, em 2012 entrou em vigência no Brasil a Lei $n^{\circ}$ 12.587, que institui a Política Nacional de Mobilidade Urbana (PNMU).

Nos termos do artigo $4^{\circ}$, inciso II, da PNMU, a mobilidade é uma característica da cidade, que diz respeito à facilidade de deslocamento de pessoas e bens na urbe (BRASIL, 2012). Estes deslocamentossão realizados através de veículose toda a infraestrutura como ruas e calçadas, em um tempo razoável, de modo confortável e seguro, para a realização de atividades cotidianas como trabalho, educação, serviços de saúde, cultura e desporto (VARGAS, 2008).

A PNMU exigiu que os municípios com mais de 20 mil habitantes elaborassem seus planos de mobilidade urbana (PLANMOB), devendo observar a 
acessibilidade para pessoas com deficiência e restrição de mobilidade. Dentre os Municípios que estão legalmente obrigados a elaborar seus planos, $70 \%$ não o fizeram no prazo estabelecido: abril de 2015 (ASSOCIAÇÃO NACIONAL DAS EMPRESAS DE TRANSPORTES URBANOS, 2015).

Juazeiro do Norte foi o município escolhido como base territorial para o estudo da inclusão socioespacial de munícipes com deficiência. Esta urbe tem população total de 249.939 habitantes, sendo que 67.453 (26,9\%) possuem algum tipo de deficiência; área territorial de $248.832 \mathrm{~km}^{2}$ e área urbanizada correspondendo a 95,0 \% do território. Juazeiro do Norte está localizada na Região Metropolitana do Cariri, que por sua vez está situada no Sul do Estado do Ceará no Nordeste brasileiro (IBGE, 2015).

A presente pesquisa se ocupa em saber como os juazeirenses com deficiência tem usufruído do direito fundamental de ir e vir. Para responder a tal questionamento, objetivou-se verificar as condições em que se realizam os deslocamentos de cidadãos com deficiência em Juazeiro do Norte.

Este artigo está organizado do seguinte modo: em seguida a esta introdução, no primeiro tópico, é apresentada a metodologia utilizada e as respectivas etapas que envolveram a execução da pesquisa; a segunda sessão e seu respectivo sub tópico abordam o referencial teórico e os aspectos legais relativos a PNMU, a acessibilidade e a mobilidade, em contraponto à realidade encontrada no município de Juazeiro do Norte após a realização da pesquisa de campo; no terceiro item são informadas quais são, para os citadinos com deficiência, os impactos negativos oriundos da falta de um planejamento que observe a acessibilidade e a mobilidade dos espaços urbano e, por fim, são apresentadas as conclusões do estudo.

\section{ACESSIBILIDADE E MOBILIDADE PARA PESSOAS COM DEFICIÊNCIA}

Uma questão a cada dia mais urgente é a preparação das cidades em diversos aspectos para que seus cidadãos colocados à margem sejam socialmente incluídos. Dentre estes, a acessibilidade ocupa lugar de destaque.

Para propiciar a melhoria nos deslocamentos, seja por meio das vias para pedestres ou de forma motorizada mediante o uso do transporte coletivo, a PNMUdeterminou que os municípios com mais de 20 mil habitantes elaborassem Ciência e Sustentabilidade - CeS | Juazeiro do Norte v. 2, n. 1, p. 41-55, jan/jun 2016 
seus planos de mobilidade, a serem revisados a cada 10 anos, devendo contemplar não só os princípios, os objetivos e as diretrizes da PNMU, mas também a acessibilidade para pessoas com deficiência e com mobilidade reduzida (IPEA, 2012; BRASIL, 2012).

Aguiar (2010, p. 36), declara que a acessibilidade "está relacionada a oportunidade e/ou potencial disponibilizados pelo sistema de transporte e uso do solo, para que diferentes tipos de pessoas desenvolvam suas atividades". Também está relacionada a capacidade "de se atingir um determinado lugar", acrescenta a autora.

Ribeiro (2013, p. 8) assevera que, "[...] a acessibilidade é um direito humano que deve ser considerado como eixo estruturante de qualquer cidade sustentável". A carência de diálogo entre essas perspectivas compromete a garantia de direitos humanos e o pleno exercício da cidadania, uma vez que torna difícil ou impossível o acesso à cidade e seus espaços a uma fração considerável da população. Assim, elaborar diretrizes para a execução de mobilidade urbana sem observar os parâmetros de acessibilidade significa menosprezar a questão humana e social.

A acessibilidade, nos termos do artigo $4^{\circ}$, inciso III, da PNMU, é a "facilidade disponibilizada às pessoas que possibilite a todos autonomia nos deslocamentos desejados, respeitando-se a legislação em vigor" (BRASIL, 2012, p. 2).

A legislação a que a PNMU se reporta é o Decreto $n^{\circ} 5.296$ de 2 de dezembro de 2004. Este documento estabelece normas gerais e critérios básicos para a promoção da acessibilidade e versa em seu artigo $2^{\circ}$, que ficam sujeitos ao cumprimento de suas disposições, sempre que houver relação com a matéria nele regulamentada (BRASIL, 2004, p. 1):

I - a aprovação de projeto de natureza arquitetônica e urbanística, de comunicação e informação, de transporte coletivo, bem como a execução de qualquer tipo de obra, quando tenham destinação pública ou coletiva;

II - a outorga de concessão, permissão, autorização ou habilitação de qualquer natureza;

III - a aprovação de financiamento de projetos com a utilização de recursos públicos, dentre eles os projetos de natureza arquitetônica e urbanística, os tocantes à comunicação e informação e os referentes ao transporte coletivo, por meio de qualquer instrumento, tais como convênio, acordo, ajuste, contrato ou similar; e

IV - a concessão de aval da União na obtenção de empréstimos e financiamentos internacionais por entes públicos ou privados.

Ciência e Sustentabilidade - CeS | Juazeiro do Norte v. 2, n. 1, p. 41-55, jan/jun 2016 
O Decreto acima mencionado afirma ainda que a elaboração e a execução dos projetos arquitetônicos e urbanísticos devem observar aos princípios do desenho universal, tendo como referências básicas as normas técnicas de acessibilidade da Associação Brasileira de Normas Técnicas (ABNT).

O desenho universal diz respeito a(BRASIL, 2004, p. 5):

concepção de espaços, artefatos e produtos que visam atender simultaneamente todas as pessoas, com diferentes características antropométricas e sensoriais, de forma autônoma, segura e confortável, constituindo-se nos elementos ou soluções que compõem a acessibilidade.

A Norma Brasileira Regulamentadora (NBR) $n^{\circ} 9.050$ da ABNT (2004) que trata da acessibilidade à edificações, mobiliário, espaços e equipamentos urbanos assevera que a acessibilidade se perfaz com calçadas sem mudanças abruptas de nível e sem barreiras, com rampa de inclinação e larguras corretas, utilização de revestimento apropriado no piso, projeto e disposição correta do mobiliário urbano e da vegetação, colocação de piso tátil direcional e de alerta, dentre outros. "É importante evidenciar que estas medidas requerem, acima de tudo, que as rotas sejam continuas e que haja coerência no sistema implantado, além de conforto e segurança", complementa Aguiar (2010, p. 39).

A PNMU exigiu que os municípios com mais de 20 mil habitantes elaborassem seus planos de mobilidade urbana (PLANMOB), devendo observar a acessibilidade para pessoas com deficiência e restrição de mobilidade. Dentre os Municípios que estão legalmente obrigados a elaborar seus planos, $70 \%$ não o fizeram no prazo estabelecido: abril de 2015 (ASSOCIAÇÃO NACIONAL DAS EMPRESAS DE TRANSPORTES URBANOS, 2015). Dentre estes se encontra Juazeiro do Norte, município escolhido como base territorial para o estudo da inclusão socioespacial de munícipes com deficiência.

\section{CAMINHOS DA PESQUISA}

O levantamento de dados foi realizado entre os meses de agosto e dezembro de 2015, por meio de uma metodologia de pesquisa qualitativa, em função do objeto da investigação - mobilidade de pessoas com deficiência na cidade 
de Juazeiro do Norte - tratar-se de um fenômeno socioambiental complexo, cuja compreensão pode ser facilitada através de estudos multivariados dentro de uma mesma pesquisa (YIN, 2001).

Para o enfrentamento do tema foi adotado o estudo de caso e a triangulação interna (aplicação combinada de diversas técnicas de coleta de dados). $O$ estudo de caso se ajusta na abordagem qualitativa e sua relevância está no propósito de enriquecer e aprofundar a análise de situações complexas mediante o estudo de uma dinâmica específica introduzida em um determinado contexto (TRIVIÑOS, 1987). A investigação utilizou fontes múltiplas de evidências e foi estabelecido seu encadeamento:

a. Realização de revisão bibliográfica, por meio da leitura e análise de artigos científicos e documentos eletrônicos com abordagem e reflexões sobre a temática da acessibilidade e da mobilidade.

b. Realização de entrevista semiestruturada com o Sr. Jhonatas David de Lima: cadeirante e presidente da Associação Defensora das Pessoas com Mobilidade Reduzida (ANDARE). Sem impor opções de respostas, optou-se por esta modalidade de entrevista por preservar certa padronização dos questionamentos. A entrevista foi gravada com prévia autorização do informante e para a reprodução, respeitou-se a linguagem por ele utilizada.

c. Visita de campo. Nesta etapa do estudo, os pesquisadores realizaram um trajeto com o Sr. Lima pelas ruas de Juazeiro do Norte. O convite para participar da pesquisa perguntava se esta também poderia ser feita durante um deslocamento diário do entrevistado. A intenção foi observar como pessoas com deficiência realizam seus deslocamentos no município. O percurso escolhido por Lima durou cerca de 30 minutos e foi realizado de sua casa até o shopping center(há duas quadras de distância).

\section{O PROBLEMA DA MOBILIDADE EM JUAZEIRO DO NORTE}

Os pesquisadores acompanharam Lima (presidente da ANDARE), no trajeto entre sua residência e o shopping center de Juazeiro do Norte. Ao sair de sua 
residência, o informante logo tem de descer a calçada e iniciar o percurso pelo asfaltamento, pois em todo o quarteirão, a única rampa que facilita o acesso de pessoas em cadeira de rodas é localizada logo em frente à sua casa.

Questionado sobre as condições de acessibilidade em Juazeiro do Norte, Lima declarou que mesmo com uma ampla legislação que assegura o direito de ir e vir das pessoas com deficiência, "todos os dias inauguram lojas com batentes nas portas". Destacou ainda que a calçada do shopping por ele frequentado só possui rampa de acesso e um piso tátil devido a uma Ação Civil Pública movida pela ANDARE, mesmo que não instalados em total acordo com a NBR n 9.050.

$\mathrm{Na}$ Avenida Presidente Castelo Branco, Lima chamou atenção para uma rampa na calçada do shopping. O rebaixamento se encontra inadequado e apesar de haver outra rampa do outro lado da avenida, em frente a esta, o entrevistado não poderia chegar ao outro lado, pois não há rebaixamento no canteiro central. $E$ completa: "Se eu descesse aos trancos e barrancos, eu ia ser morto ali no meio. Isso passa para as pessoas a aparência de acessibilidade, passa a impressão de que está feito e isso é pior". Em seguida explica o porquê, "na falta de acessibilidade, você vai reclama, processa. $\mathrm{Na}$ aparência de acessibilidade, você vai reclamar e eles dizem que vocês são frescos demais, a gente faz e vocês ainda reclamam!".

$\mathrm{Na}$ mesma calçada do shopping, foi feita a colocação de piso tátil. No entanto, o piso apresenta danos, faltando peças em determinados pontos ao longo de sua continuidade. Observa-se também que este se interrompe antes da entrada de acesso ao local.

Sobre a importância da mobilidade para pessoas com deficiência, Lima afirma que "a mobilidade pra gente é mais preciosa do que pras pessoas que nunca perderam. A gente precisa mais da mobilidade. A gente quer se mexer, mas aí você se depara com um monte de obstáculos".

Perguntado sobre o que os sujeitos com deficiência querem, Lima relatou que, "a gente quer é estar no meio do povo, tá dentro do ônibus, tá na calçada, tá nas lojas e a gente fica cada vez mais individualizado no nosso canto porque a gente é que tá se adaptando ao meio e não o meio sendo corrigido pra gente".

Com efeito, a ausência de planejamento das vias na cidade de Juazeiro do Norte causa uma série de transtornos aos munícipes. Por não terem o passeio livre 
e adequado para a circulação, os cidadãos percorrem seus trajetos junto aos veículos, uma ameaça à integridade física destes.

Quando se trata de munícipes com deficiência, os impactos da ausência de um planejamento que promova acessibilidade e mobilidade são maiores e sentidos de forma mais contundente. Tais impactos são aprofundados na sessão a seguir.

\section{CONSEQUÊNCIAS DA AUSÊNCIA DE ACESSIBILIDADE E MOBILIDADE}

O primeiro impacto a ser analisado é o da manifestação da deficiência como um atributo incapacitante. Em que pese a diversidade humana seja um componente de qualquer sociedade, a depender de como estas se organizam, algumas manifestações da diversidade podem resultar em quadros de desigualdade pelas restrições que alguns sujeitos experimentam em razão da condição de deficiência (SANTOS, 2008).

A deficiência se apresenta a partir do momento em que a interação entre a pessoa e o ambiente é focalizada de forma mecanicista e simplificada. O ambiente e seus elementos constituintes (físicos e humanos) são vistos como se simplesmente reagissem aos sujeitos com deficiência, quando, na realidade, este ambiente constrói a manifestação da deficiência nos sujeitos (OMOTE, 1995).

Nos termos da Convenção Sobre os Direitos das Pessoas com Deficiência, a deficiência é na maioria das vezes, aquilo que a estrutura física, social e de atitude da sociedade atribui às pessoas que tem tão somente restrições em suas funcionalidades (BRASIL, 2009). Assim, quando as cidades não dispõem de infraestrutura adequada para munícipes com restrições de mobilidade, a deficiência em vez de ser uma questão de ordem pública a ser enfrentada pela sociedade e pelo Estado, passa a ser encarada como uma tragédia individual a ser reparada na esfera privada da própria pessoa com deficiência e de seus familiares.

O cenário acima apresentado inicia o processo de segregação espacial, pois nem todas as pessoas que nascem e crescem na cidade têm o direito de desfrutá-la plenamente (MELO, 2012). A exclusão espacial é a segunda consequência negativa causada pela ausência de acessibilidade e mobilidade.

A existência de obstáculos nas comunicações, atitudinais e, nomeadamente, arquitetônicos, afetam de modo mais agudo não só as populações mais carentes e 
menos protegidas, mas também os sujeitos com deficiência cuja acessibilidade e mobilidade ao espaço urbano e aos meios de transporte são drasticamente reduzidas, dificultando ou impedindo o seu deslocamento (BRASIL, 2006).

Os citadinos com deficiência, muitas vezes por falta de acessibilidade, que gera baixo índice de mobilidade, não circulam pela cidade e, por conseguinte, desconhecem muitas porções de seu território e não têm a oportunidade de apreendê-lo como totalidade.

Como consequência da privação de acesso aos espaços e serviços ofertados nas cidades, advém o terceiro impacto negativo: os munícipes com deficiência, por não conseguirem se deslocar, são alijados de seus direitos humanos e liberdades fundamentais.

As pessoas com deficiência são detentoras dos mesmos direitos que os sujeitos sem deficiência. Todavia, elas nem sempre têm acesso a estes direitos nas mesmas condições em que o fazem as demais pessoas, por causa das desvantagens impostas pela sociedade. A sociedade lhes coloca barreiras físicas, nas comunicações e de atitude (SECRETARIA NACIONAL DEPROMOÇÃO DOS DIREITOS DA PESSOA COM DEFICIÊNCIA, 2012).

O Relatório Mundial sobre a Deficiência sublinha que (ORGANIZAÇÃO MUNDIAL DA SAÚDE, 2012, p. 5):

\begin{abstract}
Em todo o mundo, as pessoas com deficiência apresentam piores perspectivas de saúde, níveis mais baixos de escolaridade, participação econômica menor, e taxas de pobreza mais elevadas em comparação as pessoas sem deficiência. Em parte, isto se deve ao fato das pessoas com deficiência enfrentarem barreiras no acesso a serviços que muitos de nós consideram garantidos há muito, como saúde, educação, emprego, transporte, e informação [...] (SIC).
\end{abstract}

Para possibilitar às pessoas com deficiência o pleno gozo de todos os seus direitos humanos e liberdades fundamentais, é importante reconhecer que o direito de locomover-se de forma autônoma e segura é primordial, pois seu exercício é condição sinequa non para os demais.

Sobre a exclusão espacial que gera a exclusão social, Broadus (2012, p. 1) afirma que:

A compreensão sobre deficiência também vem evoluindo. Cada vez mais entende-se que uma deficiência física não é apenas uma condição estática. A deficiência - e sua gravidade - dependem do ambiente em que a pessoa

Ciência e Sustentabilidade - CeS | Juazeiro do Norte v. 2, n. 1, p. 41-55, jan/jun 2016 
vive. Ou seja, se as cidades oferecessem condições para uma pessoa em cadeira de rodas sair de casa e chegar, em tempo razoável, a um local de trabalho digno, e depois do expediente ir ao cinema e achar um lugar bom para assistir ao filme, essa deficiência já não é qualificada como tão grave nos índices de mobilidade.

Da mesma forma, quando a cidade não é acessível, qualquer deficiência se torna mais séria: a pessoa com idade ativa não consegue chegar no trabalho e a criança deixa os estudos, porque não conta com escola acessível.

Quando o meio ambiente urbano não se corrige para receber em seus espaços os sujeitos com deficiência, estes são diminuídos à condição de clausura e não desempenham suas funções na sociedade (BRASIL, 2006a). Uma expressiva fatia da população que poderia qualificar-se e contribuir para o desenvolvimento local sustentável de forma ativa e plena em vez de depender de políticas públicas assistencialistas.

\section{CONSIDERAÇÕES FINAIS}

A cidade de Juazeiro do Norte ainda não atende de modo satisfatório as necessidades de deslocamento de seus munícipes, nomeadamente os que precisam de condições especiais para realizar seus trajetos. A concepção inadequada dos espaços e equipamentos públicos ou de uso coletivo, dificulta e até mesmo impossibilita que os juazeirenses com deficiência desfrutem com segurança e autonomia dos espaços, mobiliários e equipamentos urbanos, e das edificações.

Estas concepções inadequadas no município se apresentam na execução bem como na falta de acessibilidade em alguns pontos das vias públicas. Observouse a ausência de rebaixamentos em canteiros e calçadas, forçando o pedestre com deficiência a deslocar-se pelo asfaltamento, expondo-se a riscos; e a disposição inadequada de piso tátil, com falhas na continuidade, dificultando o direcionamento das pessoas que dele necessitam.

Mais que deixar de receber recursos federais para custear obras de mobilidade, a não elaboração do PLANMOB, no qual Juazeiro do Norte está legalmente obrigado, perpetua o quadro de segregação espacial vivenciado pelos munícipes com deficiência.

Quando pessoas com deficiência nascem e crescem em cidades que não favorecem sua inclusão, elas terão suas oportunidades de crescimento pessoal e 
profissional profundamente comprometidas devido à ausência de acessibilidade, ao baixo acesso à saúde, à educação, ao emprego, à cultura e ao lazer. Mencione-se ainda que por não poderem desfrutar de um leque de serviços e oportunidades, os citadinos com deficiência são inevitavelmente reduzidos à clausura e Juazeiro do Norte deixa de aproveitar grande parcela de seu potencial humano que poderia contribuir para seu sustentável desenvolvimento.

Quebrar esse ciclo em que exclusão gera exclusão é uma exigência urgente que depende de escolhas corajosas. Essas escolhas devem ter como pano de fundo a elaboração do PLANMOB, ter como vigas mestras os princípios, objetivos e diretrizes da PNMU e o PLANMOB deve adotar, de modo transversal, as questões pertinentes às pessoas com deficiência, ou seja, adotar o conceito de desenho universal previsto nos Decretos no 5.296 de 2004 e no 5.904 de 2006, e na NBR nº 9.050 de 2004.

Juazeiro do Norte exercerá sua função social enquanto cidade e tornará seus habitantes com deficiência protagonistas, em um contexto de desenvolvimento, quando mitigar as desigualdades; promover a inclusão territorial, acesso aos serviços básicos e equipamentos sociais e proporcionar melhoria nas condições urbanas no que se refere à mobilidade e acessibilidade, possibilitando autonomia nos deslocamentos e respeitando a legislação vigente.

\section{SOCIO-SPATIAL AND INCLUSION OF PEOPLE WITH DISABILITIES: A CHALLENGE TO JUAZEIRO DO NORTE MUNICIPALITY-STATE OF CEARÁ, BRAZIL}

Located in the metropolitan region of Cariri, Juazeiro do Norte city, has a total population of 249.939 habitants, among these $67.453(26,9 \%)$ have some kindof disability. The significant in cid en ce of people with disability yand your singularity, impose a challenge to the municipality in question: the inclusion of this part of the population in your daily lives. This research a im stove rify the conditions in which they perform the displacements of citizens with disabilities in Juazeiro do Norte city are performed. The qualitative research is characterized as a case study and data collection technique susedwere interviews and field visits. It was observed in the elected city the inadequate design ofs paces.. It was not ed the absence of down-grades in flower bed sand sidewalks, forcing pedestrians with disabilities to move byasp haltpaving and the inadequate arrange men tof tactile floor with gaps in continuity. Juazeiro do Norte city still does no tans wer satis factorily shift in gneeds of its citizens, especially those with a disability. The inappropriate design of public spaces and of the equipments or of the collective use equipments, coupledwiththeabsenceofanurbanmobilityplanwhichmeetstheaccessibility for people with disabilities,in der in gand preventing that juazeirenses with disabilities en joy thes paces, furnitures, urban equipment sand buildings, with security and autonomy.

Keywords: Urban Mobility. Urban Planning. Accessibility.

Ciência e Sustentabilidade - CeS | Juazeiro do Norte v. 2, n. 1, p. 41-55, jan/jun 2016 


\section{REFERÊNCIAS}

AGUIAR, Fabíola de Oliveira. Acessibilidade relativa dos espaços urbanos para pedestres com restrições de mobilidade. 2010. $170 \mathrm{f}$. Tese (Doutorado em Planejamento e Operação de Sistemas de Transportes) - Escola de Engenharia de São Carlos, Universidade de São Paulo, São Carlos, 2010. Disponível em: $<$ http://www.teses.usp.br/teses/disponiveis/18/18144/tde-21042010-193924/ptbr.php>. Acesso em: 1 dez. 2015.

ASSOCIAÇÃO BRASILEIRA DE NORMAS TÉCNICAS. NBR 9.050: Acessibilidade a edificações, mobiliário, espaços e equipamentos urbanos. Rio de Janeiro, 2004. 97p. Disponível em:

<http://www.pessoacomdeficiencia.gov.br/app/sites/default/files/arquivos/\%5Bfield_g enerico_imagens-filefield-description\%5D_24.pdf>. Acesso em: 1 dez. 2015.

ASSOCIAÇÃO NACIONAL DAS EMPRESAS DE TRANSPORTES URBANOS. Menos de $30 \%$ das principais cidades brasileiras possuem plano de mobilidade urbana. NTU Urbano, Brasília, v. 3, n. 13, p. 14-19, jan/fev. 2015. Disponível em: <http://novoportal.ntu.org.br/upload/Publicacao/Pub635629598079065291.pdf>. Acesso em: 14 ago. 2015.

BRASIL. Decreto $n^{\circ} 5.296$ de 2 de dezembro de 2004. Regulamenta as Leis nos 10.048 , de 8 de novembro de 2000 , que dá prioridade de atendimento às pessoas que especifica, e 10.098, de 19 de dezembro de 2000, que estabelece normas gerais e critérios básicos para a promoção da acessibilidade das pessoas portadoras de deficiência ou com mobilidade reduzida, e dá outras providências. Diário Oficial da União, Brasília, DF, 03 de dezembro de 2004. Disponível em: <http://www.planalto.gov.br/ccivil_03/_ato2004-2006/2004/decreto/d5296.htm>. Acesso em: 4 set. 2015.

. Decreto $n^{\circ} 5.904$ de 21 de setembro de 2006. Regulamenta a Lei no 11.126, de 27 de junho de 2005, que dispõe sobre o direito da pessoa com deficiência visual de ingressar epermanecer em ambientes de uso coletivo acompanhada de cão-guia e dá outras providências.Diário Oficial da União, Brasília, DF, 22 de setembro de 2006. Disponível em:

<http://www.planalto.gov.br/ccivil_03/_ato2004-2006/2006/Decreto/D5904.htm>. Acesso em: 1 dez. 2015.

. Ministério das Cidades.Caderno 3- Implementação do Decreto no

5.296/04 para construção da cidade acessível. 2006ª 114 p. Disponível em: <http://www.cidades.gov.br/images/stories/ArquivosSEMOB/Biblioteca/BrasilAcessiv elCaderno03.pdf >. Acesso em: 14 ago. 15. 
. Decreto $n^{\circ}$ 6.949, de 25 de agosto de 2009. Promulga a Convenção Internacional sobre os Direitos das Pessoas com Deficiência e seu Protocolo Facultativo. Diário Oficial da União,Brasília, DF, 25 ago. 2009. Disponível em: <http://www.planalto.gov.br/ccivil_03/_ato2007-2010/2009/decreto/d6949.htm>. Acesso em: 12 ago. 14.

. Lei no 12.587, de 03 de janeiro de 2012. Institui as diretrizes da Política Nacional de Mobilidade Urbana; revoga dispositivos dos Decretos-Leis nos 3.326, de 3 de junho de 1941, e 5.405, de 13 de abril de 1943, da Consolidação das Leis do Trabalho (CLT), aprovada pelo Decreto-Lei no 5.452, de 10 de maio de 1943, e das Leis nos 5.917, de 10 de setembro de 1973, e 6.261, de 14 de novembro de 1975; e dá outras providências. Diário Oficial da União, Brasília - DF, 04 jan. 2012.

Disponível em:

<http://www2.camara.leg.br/legin/fed/lei/2012/lei125873janeiro2012612248publicaca ooriginal-134894-pl.html>. Acesso em: 14 ago. 15.

. Condições de Vida das Pessoas com Deficiência no Brasil. 2013.

Disponível em:

<http://www12.senado.gov.br/institucional/datasenado/pdf/DataSenadoPesquisaCon dicoes_de_Vida_das_Pessoas_com_Deficiencia_no_Brasiln.pdf $>$. Acesso em: 30 nov. 2015.

BROADUS, Victória. Mobilidade para deficiente físico é desafio a vencer no Brasil. 2012. Disponível em:<http://www.mobilize.org.br/noticias/1693/mobilidadepara-deficiente-fisico-e-desafio-a-vencer-no-brasil.html>. Acesso em: 1 dez. 2015.

INSTITUTO BRASILEIRO DE GEOGRAFIA E ESTATÍSTICA. Histórico de Juazeiro do Norte - Ceará. 2015. Disponível em:

$<$ http://www.cidades.ibge.gov.br/painel/historico.php?lang=\&codmun=230730\&searc $\mathrm{h}=$ ceara|juazeiro-do-norte|infograficos:-historico>. Acesso em: 22 nov. 2015.

INSTITUTO DE PESQUISAS ECONÔMICAS APLICADAS. Comunicado 128 - A Nova Lei de Diretrizes da Política Nacional de Mobilidade Urbana. 2012. Disponível em: <http://www.ipea.gov.br/portal/images/stories/PDFs/comunicado/120106_comunicad oipea128.pdf>. Acesso em: 13 set. 15.

MELO, Maria do Socorro Ribeiro de. Transporte coletivo urbano e acessibilidade na área central de Teresina: um instrumento na (re)organização do espaço. Disponível em: <http://www.geociencias.ufpb.br/posgrad/sernne/artigo51.pdf>. Acesso em: 14 out. 15. 
OMOTE, Sadao. A integração do deficiente: um pseudo-problema científico. Temas em Psicologia. Ribeirão Preto, v. 3, n. 2, p.55-62, ago. 1995. Disponível em: <http://pepsic.bvsalud.org/pdf/tp/v3n2/v3n2a07.pdf>. Acesso em: 05 jul. 2016.

ORGANIZAÇÃO MUNDIAL DA SAÚDE. Relatório mundial sobre a deficiência. Tradução Lexicus Serviços Lingüísticos. São Paulo, 2012, 334 p. Disponível em: <http://whqlibdoc.who.int/publications/2011/9788564047020_por.pdf>. Acesso em: 25 nov. 14.

RIBEIRO, Fernando Antônio Medeiros de Campos.O que esperar da Reunião da ONU sobre deficiência e desenvolvimento. Pauta Inclusiva. Brasília, n. 8, p. 4, jun. 2013. Disponível em:

<http://www.pessoacomdeficiencia.gov.br/app/sites/default/files/arquivos/\%5Bfield_g enerico_imagens-filefield-description\%5D_48.pdf>. Acesso em: 15 ago.14.

SANTOS, Wederson Rufino dos. Pessoas com deficiência: nossa maior minoria. Physis. Rio de Janeiro, v. 18, n. 3, p.501-510, set. 2008. Disponível em: <http://www.scielo.br/pdf/physis/v18n3/v18n3a08.pdf>. Acesso em: 28 mar. 2015.

SECRETARIA NACIONAL DEPROMOÇÃO DOS DIREITOS DA PESSOA COM DEFICIÊNCIA. Cartilha do Censo 2010 - Pessoas com deficiência.Brasília: SDHPR/SNPD, 2012. Disponível em:

<http://www.pessoacomdeficiencia.gov.br/app/sites/default/files/publicacoes/cartilhacenso-2010-pessoas-com-deficienciareduzido.pdf>. Acesso em 10 out. 2015.

SOUZA, Fábio de; PASQUALETTO, Antonio. Tópicos de mobilidade urbana.

Revista Estudos. Goiânia, v. 40, n. 3, p. 311-320, jun./ago. 2013. Disponível em: <http://revistas.ucg.br/index.php/estudos/article/viewFile/2922/1792>. Acesso em: 13 jul. 2015.

TRIVIÑOS, Augusto Nibaldo Silva. Introdução à pesquisa em ciências sociais:a pesquisa qualitativa em educação. São Paulo: Atlas, 1987.

VARGAS, HelianaComin. (I) Mobilidade urbana nas grandes cidades.URBS, São Paulo, n. 47, ano XII, p 7-11, jul./ago./set. 2008. Disponível em:

<http://www.fau.usp.br/depprojeto/labcom/produtos/2008_vargas_imobilidade.pdf>. Acesso em: 12 abr. 2015.

YIN, Robert K. Estudo de caso: planejamento e métodos. Porto Alegre: Bookman, 2001. 